\title{
DOSSIÊ
}

\section{Os impactos da lei 10.639/03 nos cursos de Licenciatura em Letras da Universidade Federal de Catalão}

\author{
The impacts of Law 10.639/03 on the Licenciatura in \\ Letras courses at the Federal University of Catalão
}

\author{
Maria Helena de Paula \\ Doutora em Linguística e Lingua Portuguesa pela UNESP \\ Professor na UFG - Catalão \\ mhp.ufgcatalao@gmail.com
}

Carolina Faleiros Felicio

Graduanda em Letras na UFG - Catalão

cffelicio4@gmail.com

\begin{abstract}
RESUMO: Em 2003, foi aprovada a Lei 10.639, tornando obrigatório o ensino, em todos os níveis da educação, da história e da cultura afro-brasileira e africana, mas aparentemente, a inclusão desses temas no ensino se dá lentamente. Este estudo apresenta como se dá a aplicação da Lei 10.639/03 nos cursos de Licenciatura em Letras da UFCAT, a partir da análise do Projeto Pedagógico dos cursos e dos horários semestrais de oferta de disciplinas, nos últimos dez anos. Apesar de haver pesquisas sobre o tema na Unidade Acadêmica, concluímos que seus resultados são pouco aplicados nas duas licenciaturas. Apresentam-se, ainda, estratégias para que a lei seja cumprida, pela sua obrigatoriedade e a necessidade de se combater o preconceito e transformar as relações étnico-raciais, objetivando auxiliar na formação docente dos alunos, por meio de discussões e reflexões críticas para um ensino voltado às relações étnico-raciais.
\end{abstract}

PALAVRAS-CHAVE: Formação Docente. Lei 10.639/03. Cultura afro-brasileira e africana.

ABSTRACT: In 2003, Law 10.639 was passed, making teaching compulsory Afro-Brazilian and African culture and culture at all levels of education; but apparently, the inclusion of these themes in teaching occurs slowly. This study presents how the Law 10.639/03 is applied in the UFCAT's Letters Degree courses, based on the analysis of the Pedagogical Project of the courses and the semiannual schedules of course offerings, over the last ten years. Although there is research about Afro-Brazilian and African culture in the Academic Unit, we conclude that its results are little applied in both degrees. Strategies are also presented for the law to be complied with, due to its mandatory nature and the need to fight prejudice and transform ethnic-racial relations, aiming to assist in teacher education of students, through discussions and critical reflections for a teaching focused on ethnicracial relations. 
Revista do Corpo Discente do Programa de Pós-Graduação em História da UnB

Em TEMPO DE HISTóRIAS | Brasília-DF | n. 36 | p. 348-369 | jan./jun. 2020.

ISSN 2316-1191

KEYWORDS: Teacher Education. Law 10.639/03. Afro-Brazilian and African culture.

\section{Palavras iniciais}

A escravização vigorou por quase 400 anos no Brasil, desde o século XVI até o ano de abolição da escravatura. Dos africanos que foram retirados de suas terras e famílias pelos colonizadores para serem vendidos como escravos, cerca de 40\% deles teve como destino a colônia portuguesa na América (REIS; GOMES, 1996). A participação desses povos na constituição social brasileira é enorme, mas infelizmente não é visibilizada e valorizada.

Em 1888, o ato "libertador" da abolição da escravatura não passou de um assassinato em massa da população negra brasileira (NASCIMENTO, 1978). Após a "liberdade" assinada pela Princesa Isabel nada foi feito para que os negros fossem inseridos na sociedade, tivessem condições mínimas para a sobrevivência e oportunidades dignas de trabalho. Atualmente existem políticas afirmativas que buscam reparar e combater as desigualdades e discriminações sofridas pelos afrodescendentes, um exemplo é a Lei 10.639/03, a qual será foco deste trabalho.

$\mathrm{Na}$ Educação Básica, quando se pensa no ensino da história e da cultura africana e afro-brasileiras, sempre nos deparamos com conteúdos voltados para o período da colonização e da escravatura no Brasil, raras são as vezes em que são abordadas questões relacionadas à história e à cultura deste povo na constituição da identidade brasileira. Para repensar e entender esse quadro, em 2003 foi aprovada a Lei 10.639, que alterou a Lei 9.394/96, tornando obrigatório, em todos os sistemas de educação, o ensino da história e da cultura africana e afro-brasileira. Em 2008, a referida lei foi alterada pela Lei 11.645 , que acrescentou a obrigatoriedade do ensino da cultura e da história dos povos indígenas. Em que pese às duas leis serem de grande importância e complementares, o foco deste estudo residirá no disposto na Lei $10.639 / 03$.

Assim, a pesquisa investiga a aplicação da referida Lei nos cursos de Licenciatura em Letras da Universidade Federal de Catalão (UFCAT), além de elaborar propostas e estratégias para a devida aplicação da lei supracitada. As propostas serão apresentadas futuramente para o colegiado da Unidade Acadêmica de Letras e Linguística (UALL), ensejando contribuir com discussões em torno da formação do professor de Língua Portuguesa, visto que os futuros professores precisam ter conhecimentos da história e da cultura afro-brasileira e africana para, de fato, disseminarem aos seus alunos as diversas contribuições para a constituição e formação identitária da sociedade brasileira.

\section{Metodologia}

Primeiramente, realizou-se o levantamento do Projeto Pedagógico de Curso (PPC) e da matriz curricular dos cursos de Letras-Português e Letras-Português/Inglês 
Revista do Corpo Discente do Programa de Pós-Graduação em História da UnB

Em TEMPO DE HISTÓRIAS | Brasília-DF | n. 36 | p. 348-369 | jan./jun. 2020.

ISSN 2316-1191

da UFCAT, que se encontram disponíveis no site ${ }^{1}$ da UALL. Posteriormente, foi feita a análise desses documentos para verificar quais disciplinas poderiam efetivar o disposto na Lei 10.639/03.

Após elencar as disciplinas, verificou-se a quantidade de vezes que foram ofertadas nos cursos de Letras, o que foi possível com a disponibilização feita pela UALL dos horários confeccionados a partir de 2010. Logo após, iniciou-se a pesquisa em sites específicos para coletar materiais que abordassem sobre a Lei 10.639/03. Inicialmente, a pesquisa foi feita no site Domínio Público em agosto de 2018, que permitiu ter acesso à dissertação de Freitas (2009), intitulada "A cor da metáfora: o racismo no livro didático de Língua Portuguesa".

O levantamento de pesquisas continuou, em agosto e setembro de 2018, no Banco de Teses da Capes, que possibilitou o acesso a diversos estudos referentes à Lei citada. Ante a variedade de pesquisa na plataforma e os objetivos da pesquisa, selecionaram-se cem (100) estudos sobre a temática, para leitura e possível coleta de referencial teórico.

Por último, o levantamento bibliográfico foi feito no Google Acadêmico, com a inserção de palavras-chave como "lei 10.639/03", "lei 10.639/03 langue" e "lei 10.639/03 linguistic". Essa plataforma também oferece uma grande quantidade de textos, dos quais se selecionaram aqueles mais pertinentes à proposta deste trabalho. A pesquisa no Google Acadêmico foi feita durante toda a realização deste estudo, uma vez que a internet se mostra uma grande aliada como um ambiente onde são disponibilizados e atualizados diversos materiais acadêmicos.

Além do levantamento bibliográfico nas plataformas online, realizou-se a leitura de literatura voltada para o racismo e para a história e a cultura africanas e afrobrasileiras, em livros disponíveis na biblioteca da UFG/RC e no acervo particular das autoras desta pesquisa.

A pesquisa bibliográfica permitiu observar que são levantadas diversas questões sobre a Lei 10.639/03 e a sua aplicação nas instituições de ensino. Vários estudos analisam a representação do sujeito negro nos livros didáticos, verificam a efetivação da Lei em escolas da Educação Básica, elaboram maneiras de aplicar a Lei e abordam sobre a formação de professores. O levantamento e os estudos disponíveis nas plataformas online também possibilitaram aumentar o repertório de informações sobre a Lei 10.639/03 e sua aplicabilidade.

Os autores Domingues (2007) e Aquino (2016) foram utilizados para discorrer sobre alguns dos aspectos históricos que resultaram na criação da Lei 10.639 de 2003. Já as discussões teóricas de Almeida (2018) e Moraes (2013) possibilitaram compreender o racismo estrutural e institucional enraizado na sociedade. Como parte das estratégias, foram sugeridas obras teóricas e literárias para compor a bibliografia das disciplinas dos cursos de Letras da UFCAT, uma vez os referenciais disponíveis na matriz curricular não possibilitam a aplicação e discussões sobre os conteúdos pertinentes a Lei 10.639/03.

${ }_{1}^{1}$ Disponível em: https://letras.catalao.ufg.br/ Acesso em: 09 ago. 2018. 
Revista do Corpo Discente do Programa de Pós-Graduação em História da UnB

Em TEMPO DE HISTÓRIAS | Brasília-DF | n. 36 | p. 348-369 | jan./jun. 2020.

ISSN 2316-1191

Após as etapas citadas, fez-se o levantamento de ações que os cursos de Letras oferecidos pela UFCAT, juntamente aos docentes, já realizaram para cumprir com a Lei 10.639/03, além de expor as estratégias e propostas para que, de fato, a lei seja efetivada e possa contribuir com a formação de professores de Língua Portuguesa.

\section{O movimento negro e a Lei 10.639 de 2003}

A aprovação da Lei 10.639/03 deve-se, principalmente, às incessantes lutas do Movimento Negro brasileiro. Conforme aponta Domingues (2007), após a Proclamação da República e diante da marginalização da população negra, esta começou a instituir movimentos de mobilização e a criar grupos para tratar da questão racial no Brasil. Alguns dos grupos que surgiram foi o "Club 13 de Maio dos Homens Pretos (1902), o Centro Literário de Homens de Cor (1903), a Sociedade União Cívica dos Homens de Cor (1906) [...], a Associação Protetora dos Brasileiros Pretos (1917)" (DOMINGUES, 2007, p. 103).

Junto aos movimentos, surge a imprensa negra com jornais focados em combater o preconceito e tratar de questões dos mais diversos âmbitos relacionados à população negra. Domingues (2007) elenca alguns dos jornais que surgiram à época em diversos estados brasileiros como: O Clarim da Alvorada (1924-SP), Raça (1935MG) e Alvorada (1907-RS).

Conforme aponta Aquino (2016), por meio da arte e da imprensa negra os movimentos buscavam conscientizar as pessoas e resgatar a memória do afrodescendente. Ainda conforme a autora, "o Movimento Negro no Brasil - com estratégias que envolviam arte, cultura, política e a imprensa [...] - organizou-se para que negros fossem ouvidos, vistos e incluídos na pauta de discussão, por toda exclusão causada no período colonial" (AQUINO, 2016, p. 23).

Em 1931, na cidade de São Paulo é fundada a Frente Negra Brasileira (FNB), considerada a entidade negra mais importante do século $\mathrm{XX}$, com grupos e filiais nos vários estados brasileiros, que conseguiu fazer com que o Movimento Negro Brasileiro se tornasse um movimento de massa. A FNB buscava o fortalecimento da identidade coletiva do negro no Brasil e tentava soltar-se "das ideias de submissão e do apagamento da história e da cultura a qual o negro continuava sendo submetido" (AQUINO, 2016, p. 31). Em 1936, a FNB torna-se um partido político, mas devido à instauração da ditadura do Estado Novo, no ano de 1937 é extinta juntamente com outras organizações políticas (DOMINGUES, 2007).

No Rio de Janeiro, em 1944, é fundado outro importante grupo: o Teatro Experimental do Negro (TEN). Inicialmente, a proposta era de formar um grupo teatral constituído por atores negros, mas acabou ampliando-se e atuava nas diversas áreas da sociedade: na imprensa, com a publicação do Jornal Quilombo; na educação, oferecendo cursos de alfabetização, organizando o I Congresso do Negro Brasileiro, dentre outros (DOMINGUES, 2007). O Teatro Negro Experimental é extinto em 1968 e, 10 anos depois, em 1978 é fundado o Movimento Negro Unificado (MNU), um marco na história dos protestos e reinvindicações das organizações negras, visto que 
Revista do Corpo Discente do Programa de Pós-Graduação em História da UnB

Em TEMPO DE HISTÓRIAS | Brasília-DF | n. 36 | p. 348-369 | jan./jun. 2020.

ISSN 2316-1191

"desenvolveu-se a proposta de unificar a luta de todos os grupos e organizações antirracistas em escala nacional” (DOMINGUES, 2007, p. 114).

O MNU foi responsável por atuar em diversas áreas da sociedade, dentre elas a educacional, propondo a revisão de conteúdos preconceituosos nos livros didáticos, "a reavaliação do papel do negro na história do Brasil, e por fim, erigiu-se a bandeira do ensino da história da África nos currículos escolares” (DOMINGUES, 2007, p. 115). Aqui nota-se a preocupação com os conteúdos voltados à valorização da história da população negro.

Como aponta Nascimento (1978), em todos os níveis de ensino a educação é eurocêntrica, exaltando a Europa - assim era no século XX e atualmente existem poucas diferenças, mesmo com os avanços e as políticas afirmativas.

Se consciência é memória e futuro, quando e onde está a memória africana, parte inalienável da consciência brasileira? Onde e quando a história da África, o desenvolvimento de suas culturas e civilizações, as características do seu povo, foram ou são ensinadas nas escolas brasileiras? Quando há alguma referência ao africano ou negro, é no sentido do afastamento e da alienação da identidade negra (NASCIMENTO, 1978, p. 95).

Os questionamentos levantados pelo autor demonstram que não havia ensino voltado para a história e a cultura africanas e afro-brasileiras ou para as contribuições das populações negras na constituição histórica do Brasil. Assim, as reivindicações na esfera educacional ganham força com o MNU, mas é em 1999 que surge o projeto de Lei $\mathrm{n}^{\circ} 259$ dispondo sobre a obrigatoriedade do ensino que atendesse a esta população.

Este projeto de Lei resultou na criação da Lei 10.639 aprovada em 09 de janeiro de 2003 pelo então Presidente da República, Luiz Inácio Lula da Silva. A lei sancionada prevê que:

Art. 26-A. Nos estabelecimentos de ensino fundamental e médio, oficiais e particulares, torna-se obrigatório o ensino sobre História e Cultura Afro-Brasileira.

$\S 1^{\circ} \mathrm{O}$ conteúdo programático a que se refere o caput deste artigo incluirá o estudo da História da África e dos Africanos, a luta dos negros no Brasil, a cultura negra brasileira e o negro na formação da sociedade nacional, resgatando a contribuição do povo negro nas áreas social, econômica e política pertinentes à História do Brasil.

$\S 2^{\circ}$ Os conteúdos referentes à História e Cultura Afro-Brasileira serão ministrados no âmbito de todo o currículo escolar, em especial nas áreas de Educação Artística e de Literatura e História Brasileiras.

Além da obrigatoriedade do ensino da história e da cultura africanas e afrobrasileiras nas instituições de ensino, a Lei 10.639/03 instituiu a inclusão no calendário escolar do dia 20 de novembro como o "Dia Nacional da Consciência Negra". Após a promulgação da referida lei, o Parecer do CNE/CP 03/2004 e a Resolução CNE/CP 01/2004 instituíram as Diretrizes Curriculares Nacionais para a Educação das Relações Étnico-Raciais e para o Ensino de História e Cultura Afro-Brasileira, que 
Revista do Corpo Discente do Programa de Pós-Graduação em História da UnB

Em TEMPO DE HISTÓRIAS | Brasília-DF | n. 36 | p. 348-369 | jan./jun. 2020.

ISSN 2316-1191

“constituem-se de orientações, princípios e fundamentos para o planejamento, execução e avaliação da Educação, e têm por meta, promover a educação de cidadãos atuantes e conscientes no seio da sociedade multicultural e pluriétnica do Brasil" (BRASIL, 2004a). Portanto, a educação para as relações étnico-raciais deverá promover a valorização e o reconhecimento da história e da cultura afro-brasileira e africana na constituição da sociedade e dos sujeitos brasileiros, combatendo o racismo e as discriminações.

A educação mostra-se a principal chave para combater o racismo, o preconceito e as discriminações que atingem as populações negras, não só visando ao enfrentamento dessas questões, mas levando informações e conhecimentos para a construção de respeito entre os sujeitos e a quebra de estereótipos tão internalizados na sociedade. Por isso, é necessário que a história e a cultura afro-brasileiras e africanas sejam ensinadas nos diversos níveis de ensino.

\section{Desenvolvimento}

\subsection{Licenciaturas em Letras da UFCAT}

Na UFCAT, há dois cursos de Licenciatura em Letras: Letras com habilitação em Português e Letras com habilitação em Inglês e Português. O curso de LetrasPortuguês foi implantado na UFCAT no ano de 1986 e é ofertado no período noturno; o de Letras-Português e Inglês foi implantado em 2009, funcionando no período matutino. Os PPCs das Licenciaturas em Letras da UFCAT passaram por modificações e foram aprovados em 2011. Importa ressaltar que os PPCs dos dois cursos apresentam pouca diferenciação no que diz respeito à grade curricular das disciplinas que os alunos devem cursar.

Os dois cursos de licenciatura possibilitam ao aluno "desenvolver sua capacidade intelectiva e criativa por meio da linguagem, considerada nas suas múltiplas funções, apreendida na diversidade das línguas e na produção literária”. Ao final do curso, o futuro docente deve estar apto para lecionar e incorporando em suas aulas os conhecimentos e práticas construídas ao longo da graduação. Conforme os PPCs, o curso também busca promover "ações que identifiquem e valorizem as diferenças, levando em conta o saber dos alunos, as experiências vividas, os significados compartilhados, as representações construídas nas interações sociais" (UFG/RC, 2011a, p. 13), mostrando-se preocupado em formar um aluno que possa repensar e transformar a realidade social.

Os cursos estão divididos em três núcleos: núcleo comum, constituído por disciplinas obrigatórias às habilitações e que caracterizam a identidade de um curso de Letras; núcleo específico que diz respeito às disciplinas optativas e obrigatórias de cada habilitação; núcleo livre que são as disciplinas optativas que o aluno pode optar por cursar ou não. A leitura dos PPCs das licenciaturas em Letras da UFCAT permitiu elencar 15 (quinze) disciplinas que poderiam de alguma forma cumprir com o disposto na Lei 10.639 de 2003: Morfologia do Português, Fonologia do Português, Sintaxe do Português, Estudo do Léxico, Estudos Diacrônicos do Português, Sociolinguística, 
Revista do Corpo Discente do Programa de Pós-Graduação em História da UnB Em TEMPO DE HISTÓRIAS | Brasília-DF | n. 36 | p. 348-369 | jan./jun. 2020.

ISSN 2316-1191

Linguística Antropológica, Literatura Brasileira (1, 2, 3), Literatura Infantil (1, 2), Literaturas em Lingua Portuguesa, Cultura Brasileira e Análise do Discurso.

Desse total, oito disciplinas são obrigatórias no curso de Letras-Português, as outras são optativas, que podem ou não ser ofertadas e que ficam a critério do aluno cursá-las. Do curso de Letras-Português e Inglês, três disciplinas são obrigatórias. O primeiro quadro abaixo apresenta os anos em que essas disciplinas foram ofertadas no curso de Letras-Português com base nos horários (2009 a 2019) disponibilizados pela UAEL, já o segundo quadro expõe as disciplinas ofertadas no curso de LetrasPortuguês e Inglês. As disciplinas citadas anteriormente que não foram ofertadas até $o$ momento não serão demonstradas no quadro.

Quadro 1 - Disciplinas ofertadas no curso de Letras-Português

\begin{tabular}{|l|c|l|}
\hline \multicolumn{1}{|c|}{ Disciplina } & Natureza & \multicolumn{1}{c|}{ Ano } \\
\hline Morfologia do Português & Obrigatória & Todos \\
\hline Fonologia do Português & Obrigatória & Todos \\
\hline Sintaxe do Português & Obrigatória & Todos \\
\hline Literatura Brasileira 1 & Obrigatória & Todos \\
\hline Literatura Brasileira 2 & Obrigatória & Todos \\
\hline Literatura Brasileira 3 & Obrigatória & Todos \\
\hline Literatura Infantil 1 & Obrigatória & Todos \\
\hline Literatura Infantil 2 & Optativa & 2017 \\
\hline Estudos do Léxico & Optativa & 2015,2019 \\
\hline Linguística Antropológica & Optativa & 2016 \\
\hline Sociolinguística & Optativa & 2013 \\
\hline
\end{tabular}

Fonte: Unidade Acadêmica Especial de Letras e Linguística

Quadro 2 - Disciplinas ofertadas no curso de Letras-Português e Inglês

\begin{tabular}{|l|c|l|}
\hline \multicolumn{1}{|c|}{ Disciplina } & Natureza & \multicolumn{1}{c|}{ Ano } \\
\hline Literatura Brasileira 1 & Obrigatória & Todos \\
\hline Literatura Brasileira 2 & Obrigatória & Todos \\
\hline Literatura Infantil 1 & Optativa & 2010 \\
\hline Literatura Infantil 2 & Optativa & 2017 \\
\hline Estudos do Léxico & Optativa & 2013,2019 \\
\hline Sociolinguística & Obrigatória & Todos \\
\hline Linguística & Optativa & 2014,2019 \\
\hline
\end{tabular}


Revista do Corpo Discente do Programa de Pós-Graduação em História da UnB

Em TEMPO DE HISTÓRIAS | Brasília-DF | n. 36 | p. 348-369 | jan./jun. 2020.

ISSN 2316-1191

\begin{tabular}{|l|l|l|}
\hline Antropológica & & \\
\hline Análise do Discurso & Optativa & 2010 \\
\hline
\end{tabular}

Fonte: Unidade Acadêmica de Letras e Linguística

Observa-se com o inventário que as disciplinas ofertadas todos os anos são de caráter obrigatório, enquanto que as optativas são oferecidas esporadicamente. Portanto, a melhor maneira de aplicar e discutir os conteúdos previstos pela Lei 10.639/03 seria por meio das matérias obrigatórias, uma vez que todos os alunos devem cursá-las ao longo da graduação.

As disciplinas de Cultura Brasileira e de Literaturas em Língua Portuguesa são as únicas que disponibilizam bibliografias relacionadas com a história e a cultura afrobrasileira e africana, revelando que se fossem ofertadas durante a graduação ofereceriam diversas contribuições para os futuros professores de Língua Portuguesa, na medida em que incrementariam na formação dos docentes a valorização de literaturas afro-brasileira e africana.

\subsection{Estratégias}

\subsubsection{Ações voltadas para as Africanidades}

Em 2017, a Coordenação de Pesquisa e Pós-Graduação (CPPG) e a UALL realizaram o evento ${ }^{2}$ I Seminário Internacional de Africanidades, com os objetivos de refletir sobre os aspectos da cultura afro-brasileira e africana, valorizar a cultura e a identidade africanas e sua inter-relação na configuração da cultura brasileira e debater temas sobre a história, a literatura e as tradições afro-brasileiras e africanas. $\mathrm{O}$ evento contou com rodas de conversa sobre religiões de matriz africana, questões étnico-raciais e tradições afro-brasileiras e africanas, apresentações e sessões de comunicações orais para divulgar as pesquisas realizadas por alunos e docentes de várias partes do Brasil e pesquisadores de diferentes países de África.

Até o momento realizou-se apenas a edição de 2017, caso o evento viesse a acontecer novamente seria considerável o impacto na formação dos futuros professores de Letras da UFCAT. A participação nas atividades do evento pode/poderia complementar e aumentar o repertório dos alunos, bem como instigá-los a realizar novas pesquisas visando à valorização e ao reconhecimento da história e da cultura afro-brasileira e africana. Uma proposta interessante seria de realizar o Seminário Internacional de Africanidades anualmente.

No mês de abril de 2018, o Laboratório de Estudos do Léxico, Filologia e Sociolinguística (LALEFIL) da UALL ofertou o Curso de Língua e Cultura Kimbundu, ministrado pelo professor Ezequiel Bernardo ${ }^{3}$, da Universidade Onze de Novembro,

${ }^{2}$ Site do evento disponível em: www.africanidades.catalao.ufg.br. Acesso em: 15 jun. 2019.

${ }^{3} \mathrm{O}$ professor concedeu uma entrevista à rádio Nova Liberdade, que está disponível em: https://alefil.catalao.ufg.br/p/24498-entrevista-do-prof-ezequiel-bernardo-da-universidade-onze-denovembro-cabinda-angola Acesso em: 15 jun. 2019. 
Revista do Corpo Discente do Programa de Pós-Graduação em História da UnB

Em TEMPO DE HISTÓRIAS | Brasília-DF | n. 36 | p. 348-369 | jan./jun. 2020.

ISSN 2316-1191

Cabinda (Angola) e falante nativo desta língua bantu. Vinte e seis (26) pessoas (alunos e docentes de graduação e pós-graduação da Universidade e comunidade externa) participaram ativamente do curso, que teve duração de uma semana e abordou as características desta língua de Angola e discutiu sobre as influências do Kimbundu para a cultura e o português falado no Brasil.

Promover eventos e cursos que tratam sobre história, língua e cultura afrobrasileiras e africanas é importante, não só para a comunidade acadêmica como também para a comunidade externa. Compartilhar essas informações gera o respeito e, consequentemente, quebra estereótipos e preconceitos sobre aquilo que se passa a conhecer. Provavelmente, para aqueles que participaram, as ações supracitadas muito contribuíram para as suas formações. Idealmente todos deveriam participar, mas não é o que ocorre uma vez que essas atividades não são institucionalizadas ou obrigatórias.

Importa mencionar o projeto de pesquisa intitulado Em busca da memória perdida: estudos sobre a escravidão em Goiás, coordenado pela Prof. ${ }^{a}$ Dr. ${ }^{a}$ Maria Helena de Paula, que desenvolve pesquisas desde 2010. Um dos principais objetivos do projeto é resgatar, analisar e divulgar os manuscritos sobre a escravidão em Goiás. Vários estudos já foram realizados com os manuscritos que fazem parte do projeto, como estudos históricos, sociolinguísticos, lexicais e gramaticais. Até o momento já foram concluídas uma supervisão de Pós-Doutorado, 3 dissertações, 25 Iniciações Científicas (IC), e encontram-se em andamento uma dissertação e 4 ICs. Além disso, vários textos foram publicados em livros, artigos em periódicos com Qualis e artigos em Anais de eventos. Os integrantes do projeto também fazem a divulgação de suas pesquisas em evento promovidos pela Universidade Federal de Catalão e por outras universidades.

Uma estratégia interessante para divulgar amplamente essas pesquisas, seria que o LALEFIL organizasse, anualmente ou semestralmente, colóquios com a participação dos integrantes do projeto supracitado, bem como de outros projetos desenvolvidos na UALL que contemplem a temática da Lei 10.639/03. Esses colóquios teriam como público alvo os estudantes de graduação e pós-graduação da UALL, como toda a comunidade universitária.

\subsubsection{Educação para as relações étnico-raciais}

Com relação à grade curricular dos cursos de Letras da UFCAT, a primeira estratégia seria a criação da disciplina Ensino para as relações étnico-raciais com foco na linguagem, a ser ofertada no $4^{\circ}$ ou $5^{\circ}$ período, atendendo a Resolução $\mathrm{CNE} / \mathrm{CP}$ 01/2004:

Art. $1^{\circ}[\ldots]$

$\S 1^{\circ}$ As instituições de Ensino Superior incluirão nos conteúdos de disciplinas e atividades curriculares dos cursos que ministram, a Educação das Relações Étnico-Raciais, bem como o tratamento de 
Revista do Corpo Discente do Programa de Pós-Graduação em História da UnB

EM TEMPO DE HISTóRIAS | Brasília-DF | n. 36 | p. 348-369 | jan./jun. 2020.

ISSN 2316-1191

questões e temáticas que dizem respeito aos afrodescendentes, nos termos explicitados do Parecer CNE/CP 3/2004 (BRASIL, 2004a).

Considerando que na licenciatura em Letras da UFCAT, as disciplinas voltadas para a educação como Políticas educacionais no Brasil e Fundamentos filosóficos e socio-históricos da educação são obrigatórias, haja vista que as licenciaturas devem "Capacitar os (as) profissionais de educação para [...] construir novas relações étnicoraciais; reconhecer e alterar atitudes racistas em qualquer veículo didático-pedagógico; lidar positivamente com a diversidade étnico-racial” (BRASIL, 2006, p. 126), a nova disciplina proposta também deverá ser obrigatória.

O seu escopo deverá referir questões raciais, conhecimento da legislação e documentos oficiais que dizem respeito ao tema, para deles, enquanto futuros professores, pensar em como superar as barreiras e problemas referentes à abordagem étnico-racial na Educação Básica. As discussões devem subsidiar os alunos subsídios na elaboração de estratégias de um ensino étnico-racial nas aulas de Língua Portuguesa, pois "A luta pela superação do racismo e da discriminação racial é, pois, tarefa de todo e qualquer educador, independentemente do seu pertencimento étnico racial, crença religiosa ou posição política" (BRASIL, 2004, p. 16).

O acréscimo da disciplina nos cursos de Letras da UFCAT pode contribuir com o combate ao racismo estrutural e institucional presente na sociedade. Conforme aponta Almeida (2018, p. 24), o conceito de raça foi construído socialmente e é utilizado "para neutralizar as desigualdades, justificar a segregação e o genocídio" de determinados grupos. O racismo é um tipo de sistema que tem como fundamento a raça que se manifestará, de acordo com Almeida (2018), nas práticas sociais seja conscientemente ou inconscientemente, o que leva a privilégios ou desvantagens para as pessoas. Portanto, o preconceito e a discriminação são baseados nos estereótipos e reforçados com as relações de poder, onde um grupo - mulheres, indígenas, negros - será tratado de maneira diferenciada (ALMEIDA, 2018).

Os estereótipos negativos sobre a população negra intensificaram-se com a abolição da escravatura: sem a inclusão dessa população nas estruturas sociais, a mesma passou a ocupar espaços sociais desprestigiados, assim, segundo Moraes (2013, p. 20), "crescia o número de mães solteiras, desempregadas, debilitados pelo vício no álcool, praticantes de prostituição e de criminalidade".

O imaginário negativo construído nas relações sociais também está presente nas instituições, portanto o racismo institucional mostra-se por meio da "filtragem racial realizada pelas instituições públicas" (MORAES, 2013, p. 23). Conforme o autor, uma dessas filtragens foi a busca por desenvolvimento econômico após a abolição, em que os proprietários junto com o Estado estimularam a imigração europeia, ao mesmo tempo em que enfraqueciam e eliminavam a participação da população negra na economia do país. Outro exemplo é o período da Ditadura Militar, com a disseminação dos discursos de que a população brasileira era "um só povo, sem distinção de raças e completamente coesos socialmente" (MORAES, 2013, p. 23), que apenas confirmavam as desigualdades sociais presentes no Brasil, maquiando as discriminações e os preconceitos. Percebe-se que, o tratamento desigual persistente na sociedade é reflexo 
Revista do Corpo Discente do Programa de Pós-Graduação em História da UnB

Em TEMPO DE HISTÓRIAS | Brasília-DF | n. 36 | p. 348-369 | jan./jun. 2020.

ISSN 2316-1191

da escravidão em conjunto com a falta de incentivo nas políticas públicas voltadas para a população negra e nos estereótipos negativos (MORAES, 2013).

Ainda, conforme Almeida (2018, p. 29), as instituições "passam a atuar em uma dinâmica que confere, ainda que indiretamente, desvantagens e privilégios a partir da raça", estabelecem uma relação de poder, dominadores e dominados, e o grupo que detém o poder terá o controle de determinados grupos, configurando que "as instituições são racistas porque a sociedade é racista" (ALMEIDA, 2018, p. 36, grifos do autor). Portanto, o racismo está presente em toda a organização da sociedade, nas relações sociais, políticas, econômicas, "o racismo é sempre estrutural" (ALMEIDA, 2018, p. 15) e, por ser estrutural, será naturalizado e normalizado, constituindo todo um imaginário social sobre a população negra:

[...] que é reforçado pelos meios de comunicação, pela indústria cultural e pelo sistema educacional. Após anos vendo telenovelas brasileiras um indivíduo vai acabar se convencendo que mulheres negras têm uma vocação natural para o emprego doméstico, que a personalidade de homens negros oscila invariavelmente entre criminosos e pessoas profundamente ingênuas, ou que homens brancos sempre têm personalidades complexas e [são] líderes natos, meticulosos e racionais em suas ações. (ALMEIDA, 2018, p. 51)

Esse imaginário também se refletirá na educação, que quase nunca dá espaço para a história, a cultura e a contribuição da população negra para o Brasil. Assim, percebe-se a importância da criação e aplicação da Lei 10.639/03 nas instituições de ensino, bem como da disciplina Educação para as relações étnico-raciais nos cursos de licenciatura em Letras.

No encalço da proposta de disciplina, a sua bibliografia deve contar com os documentos oficiais como a Lei 10.639/03: as Diretrizes Curriculares Nacionais para a Educação das Relações Étnico-Raciais, as Orientações e ações para a Educação das Relações Étnico-Raciais e o Plano nacional de implementação das diretrizes curriculares para educação das relações étnico-raciais.

Discussões realizadas por teóricos devem compor a bibliografia, possibilitando aos docentes e discentes debates sobre o tema, objetivando a formação de professores preocupados com o ensino das relações étnico-raciais. O livro organizado por Sansone e Pinho (2008) contém artigos que tratam sobre raça, etnia e cor e os reflexos dessa categorização nas relações sociais e institucionais, que podem contribuir com as discussões feitas em sala de aula. A obra de Gouvêa, Oliveira e Sales (2014) traz diversos textos que discorrem sobre a Lei 10.639/03 e as relações étnico-raciais nas salas de aula com experiências em diversos níveis da educação. Mattos (2008), Pereira (2014) e Ribeiro (1995) também devem constar na bibliografia, pois apresentam informações sobre a história e a cultura afro-brasileira, as religiões de matriz africana e as contribuições desses povos na constituição da nação brasileira.

A educação é um importante caminho para transformar as relações sociais e raciais porque é a porta de entrada para que todos, alunos e professores, possam combater o racismo e a discriminação. Assim, uma disciplina obrigatória que debata 
Revista do Corpo Discente do Programa de Pós-Graduação em História da UnB

Em TEMPO DE HISTÓRIAS | Brasília-DF | n. 36 | p. 348-369 | jan./jun. 2020.

ISSN 2316-1191

esses temas é o estabelecimento de políticas para o ensino das relações étnico-raciais nas Licenciaturas em Letras.

\subsubsection{Literatura}

A disciplina optativa Literaturas em Língua Portuguesa, conforme a ementa, possui foco na literatura africana e afro-brasileira e traz bibliografias que contribuem com o disposto na Lei 10.639/03, mas até o momento não foi ofertada nos cursos de licenciatura em Letras da UFCAT. É certo que não ofertar a disciplina impossibilita que o discente tenha contato com os seus conteúdos e, consequentemente, não os utilize quando atuar na Educação Básica. Para identificar as reais motivações dos dois cursos (Letras - Português, de 1986, e Letras - Português e Inglês, de 2009) não terem uma sólida política de formação de seus licenciandos no que concerne à lei 10,639/03, seja da UALL ou dos docentes, seria necessário realizar uma pesquisa meticulosa com entrevistas e questionários com os docentes desta unidade acadêmica e, a partir dos resultados, propor uma formação e um quadro teórico que os habilitem e os encorajem a assumir esta trajetória de "estabelecer uma política" para o ensino da história e da cultura afro-brasileira dentro dos cursos de Letras da UFCAT.

Cabe inferir distintas, mas intrincadas motivações, para este quadro, tais que: a) desconhecimento do corpo docente e discente da UALL sobre a importância e urgência de trazer esta discussão para o cerne dos debates em torno da formação em licenciaturas em Letras, sobretudo as que tenham o português (língua oficial oriunda de um devastador processo de colonização portuguesa) como um das habilitações, como é o caso dos dois cursos da UFCAT; b) não conhecimento crítico da formação cultural brasileira, que passa inegavelmente pela África e todos os séculos de escravização negra no Brasil; c) na pior das possibilidades e em decorrência dos dois motivos possíveis apresentados, o não engajamento por parte da UALL em trazer à baila a discussão étnico-racial para a sua política de formação de professores e de ensino de línguas. Qualquer que sejam os motivos, os cursos da UALL urgem assumir seu papel de formação docente crítica e reflexiva, em um país com o maior número de negros fora de África e que arrastou por séculos a escravização de povos deste continente.

Nesta perspectiva, a proposta inicial consiste em tornar obrigatória a disciplina Literatura em Língua Portuguesa nas duas licenciaturas em Letras da UFCAT e ampliar o conteúdo de sua bibliografia. Sendo assim, Campos (2008) e Moreira e Fonseca (2007) podem complementar a bibliografia da disciplina citada, uma vez que mostram como a história é construída dentro da literatura, utilizando-se da oralidade, do passado e da nação, e como as literaturas africanas possuem características identitárias, evidenciando a cultura, a religião, as línguas nacionais e as tradições.

Faz-se necessário citar algumas obras literárias que podem auxiliar o docente e trazer ricas contribuições para a disciplina. Entre obras literárias africanas: Vinte $e$ Cinco (1999), Terra Sonânbula (1992), Bom dia Camaradas (2014), Vendedor de Pássaros (2004), Uma história de Poligamia (2004). Entras as obras brasileiras, temos Lendas da África (2005), Ponciá Vicêncio (2003) e Becos da Memória (2006). 
Revista do Corpo Discente do Programa de Pós-Graduação em História da UnB

EM TEMPO DE HISTóRIAS | Brasília-DF | n. 36 | p. 348-369 | jan./jun. 2020.

ISSN 2316-1191

As disciplinas de Literatura Brasileira (1, 2, 3) são obrigatórias e podem proporcionar um estudo mais aprofundado das obras literárias, o que seria eficiente para a formação de professores visando ao disposto na Lei. $\mathrm{Na}$ bibliografia dessas disciplinas, seria significativo trabalhar com a poética de autores como Cruz e Sousa, Solano Trindade, Maria Firmina dos Reis e Conceição Evaristo. Além dos textos literários, as discussões teóricas feitas por Souza e Lima (2006) devem compor a bibliografia das disciplinas, pois apresentam diversos escritores afro-brasileiros e atividades para melhor compreensão dos aspectos da literatura afro-brasileira.

Os contos disponíveis na obra de Prandi (2007) podem oportunizar discussões sobre as religiões de matriz africana, que ainda são marginalizadas no Brasil. A quebra do preconceito só se dá com a compreensão dessas religiões: o Candomblé, por exemplo, era considerado uma feitiçaria e "a sua prática fora sempre reprimida pelos colonizadores e proibida pela Igreja Católica" (BAPTISTA; FORTUNATO, 2013, p. 286). Após a abolição, essa religião e seus praticantes continuaram sofrendo com as discriminações e perseguições: há pouco tempo, por exemplo, um terreiro foi destruído em Nova Iguaçu - RJ4 . Para combater ações como essas é que se faz necessário estudar e compreender, pelas vias da educação, sobre as religiões de matriz africana para quebrar os estereótipos negativos construídos e perpetuados há séculos.

Os contos de Conceição Evaristo (2011; 2014) e Maria Firmina dos Reis (1887) podem possibilitar diversas discussões sobre a mulher na literatura e os escritos afrobrasileiros, tornando conhecidas as obras dessas grandes escritoras, visto que a primeira teve um reconhecimento $\operatorname{tardio}^{5}$ e a segunda é considerada a primeira romancista brasileira.

Com relação aos romances, seria interessante que o docente trabalhasse com a obra Úrsula (1859), cujo estudo mostra-se importante não só com relação ao seu conteúdo, como também por ser de autoria feminina, um grupo que ao longo da história e ainda hoje não tem tanta visibilidade como os homens. As obras da escritora Carolina Maria de Jesus também deveriam ser destacadas durante as disciplinas, por exemplo, o livro Quarto de despejo (1960). Também é significativo incluir na bibliografia o estudo de Santos (2015), que buscou analisar as narrativas e as representações sociais presentes na obra citada.

Nas disciplinas de Literatura Infantil $(1,2)$, seria interessante apresentar obras que os futuros docentes pudessem trabalhar com os alunos, levando-os a se identificarem como sujeito negro e conhecer as culturas afro-brasileiras e africanas. Algumas obras literárias voltadas para o público infantil são: O cabelo de Lelê (2007), Bia na África (2007), Menina bonita do laço de fita (2000) e Luana: a menina que viu o Brasil neném (2000).

O ensino de literatura afro-brasileira é extremamente importante para a formação dos professores, enquanto indivíduo e disseminador de conhecimentos. Como

4 Em Nova Iguaçu, um terreiro foi depredado, conforme notícia está disponível neste link: https://g1.globo.com/rj/rio-de-janeiro/noticia/2019/03/29/terreiro-de-candomble-e-depredado-em-novaiguacu-religiosos-foram-expulsos.ghtml Acesso em: 05 jul. 2019.

${ }^{5}$ A escritora Conceição Evaristo demorou 20 anos para publicar sua primeira obra. A entrevista está disponível no seguinte link: https://www.bbc.com/portuguese/brasil-43324948 Acesso em: 01 jul. 2019. 
aponta Aquino (2016, p. 101-102), as discussões sobre o afro-brasileiro "faz parte de um processo de empoderamento e representatividade que não apenas o inclui nas discussões dentro e fora da sala de aula, mas conscientiza as pessoas não negras sobre a importância de analisar a história do Brasil de outro ponto de vista", contribuindo para o ensino das relações étnico-raciais.

O conhecimento, o estudo e a inclusão de literaturas africanas e afro-brasileira mostram-se necessário, visto que "poucas vezes fizeram parte dos conteúdos que eram objeto de ensino da escola formal e, quando o eram, esta tratou de deixar pouco esclarecida a origem étnica daqueles que produziam tais textos" (BUENO, 2015, p. 53). Isso ocorre, por exemplo, com Machado de Assis que frequentemente não é reconhecido como um escritor afro-brasileiro.

Além da função estética da literatura, a mesma permite reflexões críticas possibilitando discussões sobre "a influência da cor da pele na vida das pessoas, na valorização social que ainda impera no Brasil em relação a brancos e negros, aos índices de escolarização ainda desfavoráveis atrelados às populações afrodescendentes" (BUENO, 2015, p. 57).

Pretendeu-se, nesse tópico, apresentar a quantidade de obras literárias e teóricas que contemplam a Lei 10.639/03, além das diversas obras que não foram citadas aqui. Portanto, mesmo que determinada disciplina não apresente em sua ementa obras específicas e sabendo da existência da Lei, o docente pode e deve utilizar em suas aulas obras que permitam discutir questões teóricas da literatura e referentes à história e à cultura afro-brasileira e africana.

As sugestões de inclusões bibliográficas não devem substituir as já existentes na matriz curricular dos cursos de Letras da UFCAT, as quais devem ser complementares, oportunizando novos aprendizados aos alunos da graduação e aos docentes, focando no reconhecimento das culturas afro-brasileiras e africanas, bem como nas suas literaturas e escritores. Os professores que ministram tais disciplinas podem e devem fazer uso de outras obras, mas é necessário que a história e a cultura afro-brasileira e africana também façam parte das discussões.

\subsubsection{Linguística}

As disciplinas da área da Linguística possibilitam que o aluno conheça os vários processos - morfológicos, sintáticos, lexicais, variações - existentes na Língua Portuguesa e, consequentemente, as contribuições para a formação do português brasileiro: Morfologia do Português, Fonologia do Português, Sintaxe do Português, Estudo do Léxico, Estudos Diacrônicos do Português, Sociolinguística e Linguística Antropológica.

Para Petter e Fiorin (2017), poucos estudiosos dedicam-se aos estudos da Linguística Africana e as influências na Língua Portuguesa brasileira, o que torna necessário realizar discussões voltadas para as contribuições das línguas africanas, visto que "as palavras africanas que aqui se perpetuaram não fazem parte apenas de 
Revista do Corpo Discente do Programa de Pós-Graduação em História da UnB

Em TEMPO DE HISTÓRIAS | Brasília-DF | n. 36 | p. 348-369 | jan./jun. 2020.

ISSN 2316-1191

uma lista de lexema, mas constituem, antes, uma maneira de conceituar, de categorizar a realidade" (PETTER; FIORIN, 2017, p. 9).

A obra organizada pelos autores citados deve compor a bibliografia das disciplinas de Linguística, pois seus vários estudos contribuem para a compreensão da influência de línguas africanas no português falado no Brasil, analisando os empréstimos de origem africana e as similaridades fonéticas e gramaticais com as variedades do português vernáculo brasileiro, por exemplo, dentre outros estudos voltados para a língua.

A pesquisa de Manoel (2017) também deve compor a bibliografia linguística, uma vez que valoriza a tradição das Congadas da cidade de Catalão-GO, uma festa de cultura afro-brasileira, centenária e religiosa, repleta de significados sociais, históricos e culturais para seus participantes. $\mathrm{O}$ estudo permite discutir as inter-relações entre a língua e a cultura, proporcionando a difusão de conhecimentos sobre religiões e culturas afro-brasileiras.

Outros estudos pertinentes são os de Petter (2007), Apontes (2010), Oliveira e Leal (2009) e Anjos (2003). Além disso, os docentes podem promover discussões a partir dos estudos realizados por integrantes do Lalefil, que realizaram pesquisas relacionadas com o léxico e a escravidão negra em Goiás, permitindo estudar a história e a cultura de um povo, assim como fizeram Almeida (2017), Duarte-Silva (2013) e Pires (2015). As discussões a partir dessas obras em sala de aula podem contribuir bastante com a formação de docentes para o ensino da língua materna e para compreensão das relações entre a língua e a cultura de determinados grupos.

É notório que ainda falta no Brasil a consolidação de uma área de pesquisa nos estudos linguísticos que dê conta das contribuições de África na constituição das línguas faladas aqui. Não apenas porque professores estudam e pesquisam esparsamente no país, sobre muitas línguas africanas e seu contributo para o painel linguístico brasileiro, mas, sobretudo, porque a diversidade do mosaico linguístico africano e sua força sobre as culturas e as línguas brasileiras ainda não foram completamente estudados e conhecidos. Não se duvida que esta realidade esteja inserida no rol das políticas linguísticas nacionais e internacionais, mas é preciso avançar as pesquisas em andamento e dar início a outras, para atender a demandas que surjam no decorrer dos empreendimentos dos que se debruçam sobre este mosaico sociocultural e linguístico. É preciso colocar em diálogos os estudos de pesquisadores africanos e brasileiros sobre as línguas de seus países, pois assim ganham tempo, experiências em metodologias e resultados, e ganham todos na compreensão das relações afro-brasileiras nas línguas e literaturas destes espaços culturais e históricos.

\subsubsection{Análise do Discurso}

A disciplina de Análise do Discurso, obrigatória apenas no curso de LetrasPortuguês, possibilita discussões voltadas para várias esferas da sociedade. Com estudos voltados para as condições de produção e os efeitos de sentido produzidos pelos 
Revista do Corpo Discente do Programa de Pós-Graduação em História da UnB

Em TEMPO DE HISTÓRIAS | Brasília-DF | n. 36 | p. 348-369 | jan./jun. 2020.

ISSN 2316-1191

discursos, a disciplina permite que os docentes tenham certa autonomia com relação aos materiais utilizados em sala de aula.

Em vista disso, mostra-se relevante proporcionar discussões, por exemplo, com as músicas da rapper Karol Conka, que tratam sobre o feminismo negro, o racismo e o empoderamento feminino e das minorias, e do rapper Emicida, que, por meio das figuras de linguagem, traz para suas músicas as denúncias sociais e a realidade da população negra. Essas músicas podem oportunizar, a partir de teóricos da análise do discurso, debates a respeito de condições de produção, contexto histórico, dito e não dito, entre outros. Além disso, a análise feita por Oliveira (2018) das músicas do rapper Emicida pode contribuir significativamente para a disciplina, proporcionando debates e instigando os alunos a pensarem a condição do negro na sociedade e os motivos de determinados discursos se perpetuarem.

Outra sugestão é a inclusão na bibliografia da pesquisa de Nascimento (2017), que teve como objetivo analisar seis enunciados produzidos pelo Catupé Amarelo das Congadas de Catalão visando a compreender "os sentidos e as construções identitárias dos sujeitos congadeiros" (NASCIMENTO, 2017, p. 17). A Congada, como dito anteriormente, é uma tradição cultural religiosa da cidade de Catalão-GO existente há mais de 140 anos, pois dançadores antigos contam que a tradição iniciou-se em 1820 com a chegada de um grupo de escravos: "No princípio, os dançadores eram exclusivamente negros, que dançavam para que Nossa Senhora do Rosário, os libertassem do trabalho árduo e do sofrimento do trabalho escravo" (NASCIMENTO, 2017, p. 22). A Congada é uma manifestação cultural afro-brasileira, portanto deve fazer parte dos estudos dos alunos de graduação em Letras, uma vez que as discussões levam à valorização dessa tradição e inspirações para estudos posteriores.

\section{À guisa de conclusão}

Com a realização deste estudo, pôde-se observar que a UALL cumpre seu papel ao formar professores para o ensino da língua portuguesa, mas com relação ao ensino da história e da cultura afro-brasileira e africana ainda há muito a fazer para se alcançar a real aplicação da Lei 10.639/03 nos seus cursos. As disciplinas da grade curricular dos cursos de Licenciatura em Letras da UFCAT que são específicas para o ensino de literaturas de expressão portuguesa não são obrigatórias e, portanto, quase nunca ofertadas. Outras disciplinas, como as obrigatórias da área da Linguística, não apresentam em suas bibliografias estudos que discutam sobre a relação das línguas africanas com o português brasileiro, ficando a critério do docente, caso o mesmo tenha conhecimento, oportunizar discussão sobre o tema. As disciplinas da área da literatura também não trazem bibliografias sobre literaturas afro-brasileiras ou africanas.

Sendo assim, as propostas levantadas ao longo da pesquisa serão levadas à UALL para que, se aprovadas, possam compor o rol de bibliografias dispostas na matriz curricular das Licenciaturas em Letras. A inclusão desses referenciais irá contribuir para a aplicação da Lei 10.639/03 e com a formação dos docentes, uma vez que oportunizará que eles reflitam e apliquem os conhecimentos adquiridos durante a graduação nas salas de aula da Educação Básica. 
Revista do Corpo Discente do Programa de Pós-Graduação em História da UnB

EM TEMPO DE HISTóRIAS | Brasília-DF | n. 36 | p. 348-369 | jan./jun. 2020.

ISSN 2316-1191

O estudo e conhecimento de materiais que contemplem a Lei 10.639/03 trazem diversas contribuições, mas é necessário que todas as propostas e estratégias sejam de fato colocadas em práticas de maneira permanente. Apesar de ser um começo, incluir bibliografias específicas, organizar eventos ou tornar disciplinas obrigatórias não é o suficiente para implantar uma política duradoura de ensino e valorização das africanidades. Todos - docentes, discentes e equipe gestora da UALL - precisam caminhar juntos, para que ao mesmo tempo que efetivam a Lei, possam enfrentar o racismo, promover o respeito e reconhecer a contribuição da cultura africana e afrobrasileira para a formação identitária do Brasil.

Esta pesquisa reconhece que algumas ações já foram realizadas pela UALL e pelo seu corpo docente, mas são esporádicas e não configuram uma política de implementação da Lei 10.639/03 e de prática efetiva, em disciplinas, nas pesquisas e nas ações de extensão. Ainda, como abordado em tópico anterior, espera-se que seja realizada uma pesquisa detalhada para compreender porque determinadas disciplinas não são ofertadas, quais conteúdos sobre esta temática constituem o dia-a-dia das aulas destas licenciaturas e porque certos conteúdos não são abordados em sala de aula, além da falta de bibliografia específica nas disciplinas elencadas. Os resultados deste estudo a ser realizado poderão auxiliar, mormente, a UALL (que abriga o primeiro curso superior no sudeste de Goiás, criado em 1986), a UFCAT (nova universidade, em constituição ainda elaborando suas legislações e cujo perfil ainda está em construção) e toda a região a construir uma sólida política de educação étnicoracial e ter forte impacto na Educação Básica, com a implementação e a proposição de novas políticas que minimizem o racismo estrutural porque ampliarão o conhecimento da constituição cultural brasileira entre crianças e jovens.

Se colocadas em práticas, as estratégias apontadas no estudo em questão podem trazer significativas contribuições: valorização da história e da cultura afro-brasileira e africanas; ensino das relações étnico-raciais; desconstrução de estereótipos negativos vinculados à população negra e disseminados há séculos; combate ao racismo e ao preconceito racial. Ademais, constrói o respeito ao tornar conhecidas questões que há muito tempo são distorcidas sobre as populações negras e suas manifestações culturais.

O ensino das práticas étnico-raciais deve ocorrer em todos os níveis de ensino, para que essas questões sejam discutidas, combatidas e transformadas. Ainda há um longo caminho a trilhar, posto que as práticas de racismo estrutural e institucional estão muito internalizadas na sociedade, mas a educação mostra-se um veículo indispensável no combate aos estereótipos e ao racismo, visto que ao abordar tais conteúdos em sala de aula faz-se possível caminhar para uma educação voltada para a igualdade étnico-racial, a construção identitária de pessoas negras e o respeito e valorização da história e da cultura afro-brasileira e africana.

Espera-se que a presente pesquisa contribua com os vários estudos existentes sobre a Lei 10.639/03 e a formação de professores, além de instigar novas pesquisas desenvolvidas na Universidade voltadas para o ensino das relações étnico-raciais e da história e da cultura afro-brasileira e africana. 
Revista do Corpo Discente do Programa de Pós-Graduação em História da UnB

Em TEMPO DE HISTÓRIAS | Brasília-DF | n. 36 | p. 348-369 | jan./jun. 2020.

ISSN 2316-1191

\section{Referências}

AGUALUSA, José Eduardo. Vendedor de passados. Rio de Janeiro: Editora Gryphus, 2004.

ALMEIDA, Mayara Aparecida Ribeiro de. Nas trilhas dos manuscritos: estudo lexical sobre a escravidão negra em Catalão-GO (1861-1887). 2017. 533f. Dissertação (Mestrado em Estudos da Linguagem), Unidade Acadêmica Especial de Letras e Linguística, Universidade Federal de Goiás, Catalão, 2017.

ALMEIDA, Silvio Luiz de. O que é racismo estrutural? Belo Horizonte: Letramento, 2018.

ALMEIDA, Ndalu de. Bom dia Camaradas. São Paulo: Companhia das Letras, 2014.

ANJOS, Eliane Dantas dos. Glossário terminológico ilustrado de movimentos e golpes da capoeira: um estudo término-linguístico. 2003. 224f. Dissertação (Metrado em Letras), Faculdade de Filosofia, Letras e Ciências Humanas, Universidade de São Paulo, São Paulo, 2003.

APONTES, Selmo Azevedo. Acomodação de palavras bantu em português: algumas consequências morfofonológicas. Revista Philologus, ano 16, nº 46, Rio de Janeiro: CiFEFil, p. 41-56, Jan-Abr. 2010. Disponível em: http://www.filologia.org.br/revista 146sup/05.pdf. Acesso em: 20 jul. 2019.

AQUINO, Lianja Soares. O ensino de literaturas africanas e afro-brasileira na matriz curricular do curso de Letras, campus Araguaína. 2016, 111f. Dissertação (Mestrado) Universidade Federal do Tocantins, Campus Universitário de Araguaína, Araguaína, 2016.

BRASIL. Lei $n^{o}$ 10.639, de 9 de janeiro de 2003. Brasília: Ministério da Educação, 2003. Disponível em: http://www.planalto.gov.br/ccivil_03/leis/2003/110.639.htm Acesso em: 24 jul. 2019.

. Projeto de Lei $n^{\circ}$ 259. Brasília: Câmara dos Deputados, 1999. Disponível em: https://www.camara.leg.br/proposicoesWeb/prop_mostrarintegra?codteor=1127776\&fil en. Acesso em: 15 jun. 2019.

- Orientações e ações para Educação das Relações Étnico-Raciais. Brasília: Ministério da Educação/SECAD, 2006. Disponível em: http://portal.mec.gov.br/dmdocum ents/orientacoes_etnicoraciais.pdf. Acesso em: 20 jul. 2019.

Resolução $n^{o}$ 1, de 17 de junho de 2004. Brasília: Conselho Nacional de Educação/Conselho Pleno, 2004a. Disponível em: http://portal.mec.gov.br/cne/arquivos/ pdf/res012004.pdf Acesso em: 20 jun. 2019

Diretrizes Curriculares Nacionais para a Educação das Relações ÉtnicoRaciais e para o Ensino de História e Cultura Afro-Brasileira e Africana. Brasília: Conselho Nacional de Educação, 2004. Disponível em: http://www.acaoeducativa.org.br/fdh/wpcontent/uploads /2012/10/DCN-s-Educacaodas-Relacoes-Etnico-Raciais.pdf. Acesso em: 20 jul. 2019. 
. Plano nacional de implementação das diretrizes curriculares para educação das relações étnico-raciais e para o ensino de história e cultura afro-brasileira $e$ africana. $\quad$ Brasília, 2009. Disponível em: http://portal.mec.gov.br/index.php?option=com_docman\& view $=$ download\&alias $=10098$-diretrizes-curriculares\&Itemid=30192 Acesso em: 20 jun. 2019.

BAPTISTA, Jamile Carla; FORTUNATO; Poliana. O Candomblé na luta antirracista. Em: Cultura e religiões na contemporaneidade. LANZA, Fabio (org.). Londrina: UEL, 2013, p. 286-299.

BELEM, Valeria. O cabelo de Lelê. São Paulo: Companhia Editora Nacional, 2007.

BRAZ, Julio Emílio. Lendas da África. Rio de Janeiro: Bertrand Brasil, 2005.

BUENO, André Godoy. Literaturas africanas e afro-brasileira no Ensino Fundamental II. 2015. 119f. Dissertação (Mestrado em Letras) - Faculdade de Filosofia, Letras e Ciência Humanas, Universidade de São Paulo, São Paulo, 2015.

CAMPOS, Josilene Silva. A historicidade das literaturas africanas de língua oficial portuguesa. In: I Seminário de Pesquisa de Pós-Graduação em História-UFG/UCG. Goiânia: Anais do I Seminário de Pesquisa da Pós-Graduação em História-UFG/UCG, 2008.

CHIZIANI, Paulina. Nikeche: uma história de Poligamia. São Paulo: Editora Companhia das Letras, 2004.

COSTA, Nelzir Martins. Literaturas afro-brasileira e africanas: o desafio nos livros didáticos de língua portuguesa para o ensino médio. 2014. 142f. Dissertação (Mestrado em Ensino de Língua e Literatura). Universidade Federal do Tocantins, Araguaína, 2014.

COUTO, Mia. Terra Sonânbula. São Paulo: Editora Companhia das Letras, 2007.

DOMINGUES, Petrônio. Movimento Negro Brasileiro: Alguns apontamentos históricos. Tempo: Revista do Departamento de História da UFF, v. 12, n. 23, 2007, p. 100-122.

DREGUER, Ricardo. Bia na África. São Paulo: Editora Moderna, 2007.

DUARTE-SILVA, Luana. Irmandades de Pretos: edição e inventariação lexical em manuscritos goianos do século XVIII. 440f. Dissertação (Mestrado em Estudos da Linguagem), Universidade Federal de Goiás, Campus Catalão, Departamento de Letras, 2013.

EVARISTO, Conceição. Ponciá Vicêncio. Belo Horizonte: Mazza, 2003.

. Becos da Memória. Belo Horizonte: Mazza, 2006.

. Insubmissas lágrimas de mulheres. Belo Horizonte: Nandyala, 2011.

. Olhos d'água. Rio de Janeiro: Editora Pallas, 2014. 
FREITAS, I. S. A cor da metáfora: o racismo no livro didático de Língua Portuguesa. 2009. 203f. Dissertação (Mestrado em Letras) - Centro de Ciências Humanas, Letras e Artes, Universidade Federal da Paraíba, João Pessoa. 2009.

GOUVÊA, Fernando César Ferreira; OLIVEIRA, Luiz Fernandes de; SALES, Sandra Regina. Educação e relações étnico-raciais: entre diálogos contemporâneos e políticas públicas. Petrópolis: De Petrus et Alii; Brasília: CAPES, 2014.

JESUS, Carolina Maria de. Quarto de Despejo: diário de uma favelada. São Paulo: Ática, 2005.

MACEDO, Aroldo; FAUSTINO, Oswaldo. Luana: a menina que viu o Brasil neném. São Paulo: FTD, 2000.

MACHADO, Ana Maria. Menina bonita do laço de fita. São Paulo: Editora Ática, 2000.

MANOEL, Cássio Ribeiro. Relações linguístico-históricas no mito do achamento da Santa do Rosário nas Congadas de Catalão-Goiás. 2017. 155f. Dissertação (Mestrado em Estudos da Linguagem), Unidade Acadêmica Especial de Letras e Linguística, Universidade Federal de Goiás, Catalão, 2017.

MATTOS, Regiane Augusto de. História e cultura afro-brasileira. São Paulo: Contexto, 2008.

MORAES, Fabiana. No país do racismo institucional: dez anos de ações do GT Racismo no MPPE. Recife: Procuradoria Geral da Justiça, 2013.

MOREIRA, Terezinha Taborda; FONSECA, Maria Nazareth Soares. Panorama das literaturas africanas de língua portuguesa. Cadernos CESPUC de Pesquisa. Série Ensaios, v. 16 p. 13-69, 2007. Disponível em: http://www4.pucminas.br/imagedb/mestrado_doutorado/publicacoe s/PUA_ARQ_ARQUI20121019162329.pdf Acesso em: 30 jun. 2019.

NASCIMENTO, Abdias do. O genocídio do negro brasileiro: processo de um racismo mascarado. Rio de Janeiro: Editora Paz e Terra S/A, 1978.

NASCIMENTO, Juliano Carrupt do. O romance Úrsula de Maria Firmina dos Reis: estética e ideologia no Romantismo brasileiro. 106f. Dissertação (Mestrado em Literatura Brasileira). Faculdade de Letras, Universidade Federal do Rio de Janeiro, Rio de Janeiro: 2009.

NASCIMENTO, Wellington Reis do. Da congada catalana ao Catupé Amarelo no Facebook: uma análise dialógica do enunciado verbovocovisual. 2017. 118f. Dissertação (Mestrado) - Unidade Acadêmica Especial de Letras e Linguística, Universidade Federal de Goiás, Catalão, 2017.

OLIVEIRA, Josilvado Pires de; LEAL, Luiz Augusto Pinheiro. Capoeira, identidade e gênero: ensaios sobre a história social da capoeira no Brasil. Salvador: EDUFBA, 2009. Disponível em: https://repositorio.ufba.br/ri/bitstream/ufba/126/3/Capoeira\%20identidade \%20e\%20genero.pdf Acesso em: 02 jul. 2019. 
OLIVEIRA, Bruno. O signo marginal na construção do enunciado crítico na produção artística de Emicida. Cadernos Discursivos: Catalão, v. 1, n. 1, p. 205-225, 2018. Disponível em: https://cadis_letras.catalao.ufg.br/up/595/o/Bruno_Oliveira.pdf Acesso em: 01 jul. 2019.

PEREIRA, Amilcar Araujo (org.). Educação das relações étnico-raciais: trabalhando com histórias e culturas africanas e afro-brasileiras nas salas de aula. Brasília: Fundação Vale, 2014.

PETTER, Margarida Maria Taddoni; FIORIN, José Luiz. África no Brasil: a formação da língua portuguesa. 2. ed., $3^{a}$ reimpressão. São Paulo: Contexto, 2017.

PETTER, Margarida Maria Taddoni. Línguas Africanas no Brasil. África, n. 27-28, p. 63-89, 2007. Disponível em: http://www.revistas.usp.br/africa/article/view/96063 Acesso em: 04 jul. 2019.

PIRES, Maria Gabriela Gomes. De bens de herança a bens culturais: um estudo linguístico de autos de partilha oitocentistas de Catalão-Go. 2015. 269f. Dissertação (Mestrado em Estudos da Linguagem), Unidade Acadêmica Especial de Letras e Linguística, Universidade Federal de Goiás, Catalão, 2015.

PRANDI, Reginaldo. Contos e lendas afro-brasileiros: a criação do mundo. São Paulo: Companhia das Letras, 2007.

REIS, João José; GOMES, Flávio dos Santos. Liberdade por um fio: história dos quilombos no Brasil. Companhia das Letras, São Paulo, 1996.

REIS, Maria Firmina. A Escrava. In: Úrsula e outras obras. Brasília: Câmara dos Deputados, Edições Câmaras, 2018. Disponível em: http://bd.camara.gov.br/bd/handle/bdcamara/35999 Acesso em: 01 jul. 2019.

. Úrsula. In: Úrsula e outras obras. Brasília: Câmara dos Deputados, Edições Câmaras, 2018. Disponível em: http://bd.camara.gov.br/bd/handle/bdcamara/35999. Acesso em: 01 jul. 2019.

RIBEIRO, Darcy. O povo brasileiro: a formação e o sentido do Brasil. São Paulo: Companhia das Letras, 1995.

RIO, Ana Carla Carneiro; FERNANDES JÚNIOR, Antônio. Interdição do discurso, poder e construção do sujeito no conto A escrava, de Maria Firmina dos Reis. Anais do SILEL, v. 3, n. 1, Uberlândia: EDUFU, 2013.

SANTOS, Lara Gabriella Alves dos. Carolina Maria de Jesus: análise identitária em Quarto de Despejo - diário de uma favelada. 2015. 103f. Dissertação (Mestrado). Unidade Acadêmica Especial de Letras e Linguística, Universidade Federal de Goiás, Catalão, 2015.

SANSONE, Livio; PINHO, Osmundo Araújo (orgs.). Raça: novas perspectivas antropológicas. 2 ed. rev. Salvador: ABA EDUFBA, 2008.

SOUZA, Florentina; LIMA, Maria Nazaré. (orgs). Literatura afro-brasileira. Salvador: Centro de Estudos Afro-Ocidentais; Brasília: Fundação Cultural Palmares, 2006. 
Revista do Corpo Discente do Programa de Pós-Graduação em História da UnB

EM TEMPO DE HISTÓRIAS | Brasília-DF | n. 36 | p. 348-369 | jan.jjun. 2020.

ISSN 2316-1191

UNIVERSIDADE FEDERAL DE GOIÁS - REGIONAL CATALÃO. Projeto Pedagógico do curso de Letras: Letras Português e Inglês. Catalão: UFG/RC, 2011a. Disponível em: https://letras.catalao.ufg.br/. Acesso em: 18 ago. 2018.

UNIVERSIDADE FEDERAL DE GOIÁS - REGIONAL CATALÃO. Projeto Pedagógico do curso de Letras: Letras Português. Catalão: UAELL, 2011b. Disponível em: https://letras.catalao.ufg.br/ Acesso em: 18 ago. 2018. 